\title{
Current Trends in Anterior Cruciate Ligament Reconstruction
}

\author{
Ha Sung Kim, MD, Jong Keun Seon, MD, and Ah Reum Jo, MD \\ Department of Orthopaedic Surgery, Center for Joint Disease, Chonnam National University Hwasun Hospital, Hwasun, Korea
}

\begin{abstract}
The advances in the knowledge of anatomy, surgical techniques, and fixation devices have led to the improvement of anterior cruciate ligament (ACL) reconstruction over the past 10 years. Nowadays, double bundle and anatomical single bundle ACL reconstruction that more closely restores the normal anatomy of the ACL are becoming popular. Although there is still no definite conclusion whether double bundle ACL reconstruction provides better clinical results than single bundle reconstruction, the trend has shifted to anatomic reconstruction regardless of single bundle or double bundle techniques. We could not find any significant differences in the clinical outcomes and stability after ACL reconstruction according to the type of graft or fixation device. Therefore, surgeons should select an ideal ACL reconstruction according to the patient's condition and surgeon's experience.
\end{abstract}

Keywords: Anterior cruciate ligament, Anatomical reconstruction, graft, fixation

\section{Introduction}

Rupture of the anterior cruciate ligament (ACL) is one of the most common knee injuries. The annual incidence of the ACL injury ranges between 100,000-200,000 in $\mathrm{USA}^{1,2)}$. Due to the unsatisfactory outcomes of conservative treatment for ACL injuries, reconstruction surgery remains the treatment of choice in most young patients who want to maintain an active lifestyle. The main aims of ACL reconstruction are to restore intact knee stability and normal knee kinematics after reconstruction. Traditionally, ACL reconstruction has focused on non-anatomical single bundle reconstruction using a transtibial technique, which provides only anterior stability in knee flexion.

Owing to the better understanding of anatomy, improvement in

Received July 15, 2013; Revised October 2, 2013; Accepted October 6, 2013

Correspondence to: Jong Keun Seon, MD

Department of Orthopaedic Surgery, Center for Joint Disease, Chonnam National University Hwasun Hospital, 322 Seoyang-ro, Hwasun 519-

763 , Korea

Tel: +82-61-379-7676, Fax: +82-61-379-7894

E-mail: seonbell@jnu.ac.kr

This is an Open Access article distributed under the terms of the Creative Commons Attribution Non-Commercial License (http://creativecommons.org/licenses/by-nc/3.0/) which permits unrestricted non-commercial use, distribution, and reproduction in any medium, provided the original work is properly cited. surgical techniques, and advances in fixation devices, the single bundle ACL reconstruction has provided good clinical outcomes. However, some studies reported that $10 \%-30 \%$ of the patients with single bundle ACL reconstruction continued to show rotational instability and development of osteoarthritis ${ }^{3)}$. It has been assumed that these kinds of problems arise from lack of the posterolateral (PL) bundle in the single bundle ACL reconstructed knee. Therefore, double bundle or anatomical single bundle ACL reconstruction, which more closely restores the normal anatomy of the ACL, was proposed for the treatment of ACL injury. However, problems including the development of osteoarthritis after ACL reconstruction still persist despite significant improvement in ACL reconstruction. In this paper, we will review the current trend of ACL reconstruction with regard to surgical techniques, fixation devices, and graft materials.

\section{Operative Techniques for ACL Reconstruction}

\section{Anatomical Double Bundle ACL Reconstruction}

Single bundle ACL reconstruction has been considered the standard technique for restoring anterior instability, especially in flexion, by addressing the anteromeidal (AM) bundle only. However, $10 \%-30 \%$ of the ACL reconstructed patients complain of a feeling of rotational instability, so-called pivot-shift phenomenon $^{4)}$. Moreover, several biomechanical studies showed that single bundle reconstruction can restore anterior-posterior stabilwww.jksrr.org 
Table 1. Current Outcome Studies of Double Bundle Anterior Cruciate Ligament Reconstruction

\begin{tabular}{|c|c|c|c|c|c|c|c|c|c|}
\hline \multirow{2}{*}{$\begin{array}{l}\text { Study of } \\
\text { subgroup }\end{array}$} & \multirow{2}{*}{ Graft } & \multicolumn{2}{|c|}{ Femoral (mm) } & \multicolumn{2}{|c|}{ Tibial } & \multicolumn{2}{|c|}{ Fixation } & \multicolumn{2}{|c|}{ Tension } \\
\hline & & PL & $\mathrm{AM}$ & PL & $\mathrm{AM}$ & Femur & Tibia & $\mathrm{PL}$ & $\mathrm{AM}$ \\
\hline Yasuda et al. & Hamstring & $5-8 \mathrm{~mm}$ ant & $10: 30(6-8)$ & PCL $5 \mathrm{~mm}$ ant & PCL $7 \mathrm{~mm}$ ant & Endobutton & Staples $(\times 2)$ & $\begin{array}{l}10 \text { Flexion, } \\
30 \mathrm{~N}\end{array}$ & $\begin{array}{l}10 \text { Flexion, } \\
30 \mathrm{~N}\end{array}$ \\
\hline Vidal et al. ${ }^{8)}$ & TA allograft & Footprint & $10: 30-11: 00$ & Footprint & Footprint & Endobutton & $\begin{array}{l}\text { Interference } \\
\text { screw, staple }\end{array}$ & 45 Flexion & 10 Flexion \\
\hline $\begin{array}{l}\text { Brucker and } \\
\text { Imhoff }^{9)}\end{array}$ & Hamstring & Footprint & $10: 30-11: 00$ & Footprint & Footprint & $\begin{array}{l}\text { Interference } \\
\text { screw }\end{array}$ & $\begin{array}{l}\text { Interference } \\
\text { retroscrew }\end{array}$ & 45 Flexion & 20 Flexion \\
\hline Tohyama et al. $^{10)}$ & Hamstring & Footprint & Footprint & Footprint & Footprint & Endobutton & Spiked staples & $\begin{array}{c}10 \text { Flexion, } \\
40 \mathrm{~N}\end{array}$ & $\begin{array}{l}90 \text { Flexion, } \\
40 \mathrm{~N}\end{array}$ \\
\hline Zaffagnini et al. ${ }^{11)}$ & Hamstring & $10 \mathrm{~mm}$ ant & Footprint & Footprint & Footprint & Endobutton & Staples $(\times 2)$ & 15 Flexion & 90 Flexion \\
\hline $\begin{array}{l}\text { Suomalainen } \\
\text { et al. }{ }^{12)}\end{array}$ & Hamstring & Footprint (7) & Footprint (6) & Footprint & Footprint & $\begin{array}{l}\text { Bioabsorbable } \\
\text { screw }\end{array}$ & $\begin{array}{l}\text { Bioabsorbable } \\
\text { screw }\end{array}$ & 90 Flexion & 30 Flexion \\
\hline
\end{tabular}

PL: posterolateral, AM: anteromeidal, ant: anterior, PCL: posterior cruciate ligament, $\mathrm{N}:$ newton $\left(\mathrm{kg} \cdot \mathrm{m} / \mathrm{s}^{2}\right)$, TA: tibialis anterior tendon.

ity but not rotational stability, which means it does not restore normal rotational kinematics ${ }^{5}$.

With better knowledge of ACL anatomy, double bundle ACL reconstruction was proposed to closely restore the normal structure of the $\mathrm{ACL}^{3,6)}$. Although double bundle reconstruction is more effective than single bundle reconstruction for restoring normal knee kinematics, the operative techniques are various in terms of the fixation angle and device (Table 1$)^{7-12}$. Moreover, double bundle reconstruction techniques are technically more demanding and necessitate longer operative times and more extensive bone loss, thereby potentially rendering revision surgery more difficult. Although a recent meta-analysis study showed that double bundle reconstruction provides better results in terms of anterior stability and pivot-shift test than single bundle reconstruction ${ }^{13)}$, some studies failed to demonstrate significant comparative advantages of double bundle techniques in terms of clinical outcomes ${ }^{13,14}$. Moreover, some studies reported 3\%-16\% of tears of the PL reconstruction grafts on second-look arthroscopy after double bundle ACL reconstruction ${ }^{15)}$.

According to the literature review, although double bundle reconstruction has theoretical advantages over single bundle reconstruction in terms of restoring normal anatomy and kinematics, we could not recommend double bundle reconstruction for all patients with ACL injuries. However, double bundle techniques can be useful for specific cases of substantial rotational instability in hyper-lax knee joints and revision surgery ${ }^{16)}$.

\section{Anatomical Single Bundle ACL Reconstruction}

With regard to single bundle ACL reconstruction, Woo et al. ${ }^{17)}$ reported that the standard high femoral tunnel in ACL reconstruction resists anterior tibial loading, but it is not suf- ficient to control combined rotatory loads. Furthermore, several biomechanical studies have shown that the more anatomic low femoral tunnel has some advantages over the high femoral tunnel in terms of rotational stability ${ }^{3,18}$. Therefore, anatomical graft placement has been emphasized for restoration of normal knee kinematics in ACL reconstruction. Although anatomical double bundle reconstruction can closely restore the normal ACL anatomy, it does not provide consistently good results because of the abovementioned disadvantages. In addition, it has been known that $6 \%$ of the reconstructions lead to a rupture in the contralateral intact knee.

Attention has returned to single bundle reconstruction with grafts placed at the center of anatomical position. Recently, several biomechanical studies showed that the single bundle ACL grafts placed in the center of their anatomic insertions can provide nearly normal knee kinematics comparable to double bundle reconstruction ${ }^{14,19,20)}$. Sastre et al. ${ }^{19)}$ reported that single bundle ACL reconstruction in anatomical insertion site produced results comparable to those obtained using the double bundle technique, as determined by KT-1000 measurements, International Knee Documentation Committee scores, and pivot shift test results. In a study by Steiner et al. ${ }^{14)}$, a central anatomical single bundle ACL reconstruction was superior to the conventional non-anatomical single bundle ACL reconstruction in restoring normal anterior and rotational knee laxity.

Araki et al ${ }^{20)}$ reported that anatomical double bundle ACL reconstruction showed superior results in stability measured with an electromagnetic system than anatomical single bundle reconstruction but there was no difference in clinical outcome (KT1000 measurements, isokinetic peak muscle torque, and Lysholm score). Controversy exists regarding the fact that anatomical fem- 
oral tunnel placement can be achieved using a transtibial tunnel drilling technique. Giron et al. ${ }^{21)}$ showed that the standard transtibial technique in ACL reconstruction could not restore the anatomic femoral origin of the ACL despite some technical modifications. To address problems related to a vertical femoral tunnel, some surgeons have advocated performing independent drilling (transportal technique) through an anteromedial portal to place the femoral tunnel in the anatomical position instead of using the standard transtibial drilling technique ${ }^{3,19,22)}$. In addition, Kim et al. ${ }^{22)}$ reported excellent clinical results of anatomical ACL reconstruction using 3 portals by adding a far anteromedial portal to the frequently used 2 portals. While some studies have reported that anteromedial portal drilling could place the femoral tunnel in the anatomical position better than transtibial drilling, other studies reported that modified transtibial drilling technique can place a graft at anatomical position by adjusting flexion or rotational angle or using a flexible reamer during femoral drilling ${ }^{3,18}$. In addition, although the transtibial and transportal techniques have some advantages, outside-in technique has been recently reported as a reliable alternative. Lubowitz and Konicek ${ }^{23)}$ reported that the outside-in technique could be performed through a small incision and prevent excessively short femoral tunneling unlike the transportal technique. Seo et al. ${ }^{24)}$ suggested that there was no significant difference between the transtibial and outsidein techniques in the clinical outcome, and the outside-in technique provides superior knee joint rotational stability compare to the transtibial technique.

The standard location of a tibial tunnel was slightly posterior,

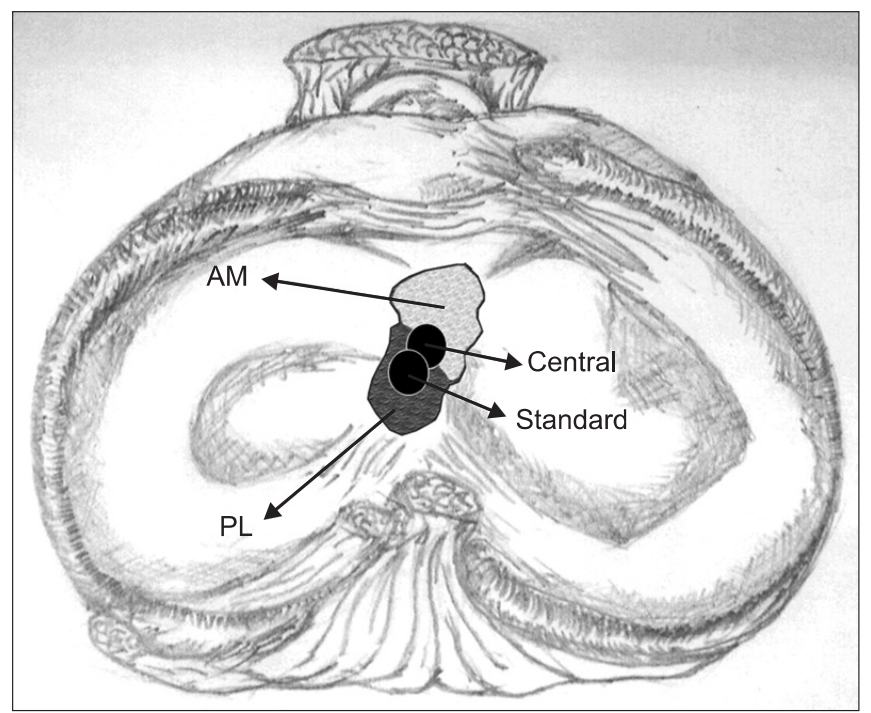

Fig. 1. Schematic drawing of the central and standard tunnel positions in anatomical single-bundle anterior cruciate ligament reconstructions. AM: anteromedial bundle, PL: posterolateral bundle. which was more close to the PL bundle than the AM bundle to prevent graft impingement at the intercondylar notch. However, in the anatomical single bundle reconstruction, many surgeons make a tibial tunnel at the center of the AM and PL bundles (Fig. $1)$.

The paradigm of anterior cruciate ligament reconstruction has shifted from isometric reconstruction to anatomic reconstruction using a single bundle or double bundle technique. Due to the questionable advantages of double bundle ACL reconstruction in clinical studies, anatomical single bundle ACL reconstruction in the mid bundle position has received more attention recently.

\section{Remnant Preserving ACL Reconstruction}

Because of the potential problem including impingement or poor visualization during reconstruction, ACL remnants are totally debrided in traditional ACL reconstruction. However it is well known that tibial remnants contain several types of mechanoreceptors. These mechanoreceptors may provide positive effects on the proprioceptive function of the knee ${ }^{25,26)}$. It has been suggested that the ACL secondarily functions as a sensory organ providing proprioceptive feedback and initiating protective reflexes and stabilizing muscular reflexes. In addition, some studies have shown that the ACL remnants provide some biomechanical stability to the knee ${ }^{25,26)}$. Moreover, posterior cruciate ligament (PCL) reconstruction with a remnant preserving technique showed better stability than PCL reconstruction without remnant tissue. Hence, some surgeons proposed remnant preserving

Table 2. Differences in the Clinical Outcomes of Remnant Preserving Anterior Cruciate Ligament (ACL) Reconstruction

\begin{tabular}{|c|c|c|c|c|c|c|}
\hline No. & Author & Yr & $\begin{array}{c}\text { No. of } \\
\text { patients }\end{array}$ & $\begin{array}{l}\mathrm{F} / \mathrm{U} \\
(\mathrm{mo})\end{array}$ & Outcomes & Study results \\
\hline 1 & $\begin{array}{l}\text { Ahn } \\
\text { et al. }^{26)}\end{array}$ & 2010 & 68 & 6.3 & MRI & $\begin{array}{l}\text { Larger ACL grafts } \\
\text { No cyclops lesion }\end{array}$ \\
\hline 2 & $\begin{array}{l}\text { Ahn } \\
\text { et al. }^{15)}\end{array}$ & 2011 & 63 & 27.7 & $\begin{array}{l}\text { MRI } \\
\text { Clinical } \\
\text { score }\end{array}$ & $\begin{array}{l}\text { Good clinical results } \\
\text { Cyclops lesions } \uparrow \text { (no } \\
\text { clinical significance) }\end{array}$ \\
\hline 3 & $\begin{array}{l}\text { Gao } \\
\text { et al. }^{29)}\end{array}$ & 2010 & 235 & 50 & $\begin{array}{l}\text { MRI } \\
\text { KT-1000 }\end{array}$ & Very good clinical results \\
\hline 4 & $\begin{array}{l}\text { Gohil } \\
\text { et al. }^{30)}\end{array}$ & 2007 & 49 & 12 & $\begin{array}{l}\text { MRI } \\
\text { KT-1000 }\end{array}$ & No difference \\
\hline 5 & $\begin{array}{l}\text { Kim } \\
\text { et al. }\end{array}$ & 2009 & 27 & 12 & Clinical & $\begin{array}{l}\text { Remnant preservation } \\
\text { could be effective } \\
\text { methods }\end{array}$ \\
\hline 6 & $\begin{array}{l}\text { Lee } \\
\text { et al. }{ }^{25)}\end{array}$ & 2008 & 42 & 35.1 & $\begin{array}{l}\text { Clinical } \\
\text { KT-1000 }\end{array}$ & $\begin{array}{l}\text { Good proprioceptive and } \\
\text { functional outcomes }\end{array}$ \\
\hline
\end{tabular}

F/U: follow-up, MRI: magnetic resonance imaging. 
Table 3. Summary of Advantages and Disadvantages of Graft Materials

\begin{tabular}{|c|c|c|c|c|}
\hline \multirow{2}{*}{ Type } & \multicolumn{3}{|c|}{ Autograft } & \multirow{2}{*}{ Allograft } \\
\hline & Patellar tendon & Hamstring & Quadriceps & \\
\hline Advantage & $\begin{array}{l}\text { Strongest healing method } \\
\text { Similar length to the ACL } \\
\text { Quicker healing process }\end{array}$ & $\begin{array}{l}\text { Small incision \& less painful harvest } \\
\text { No violation of the extensor } \\
\text { mechanism } \\
\text { Less problem with knee pain } \\
\text { Less Q-muscle atrophy, } \\
\text { Faster return of Q-muscle strength } \\
\text { Eligible for younger patients with } \\
\text { growth plates }\end{array}$ & $\begin{array}{l}\text { Rare sensory loss } \\
\text { Thicker cross sectional area } \\
\text { than BPTB }\end{array}$ & $\begin{array}{l}\text { No risk pain or scar from donor site } \\
\text { Decreased surgical time } \\
\text { Reduced Q-muscle atrophy } \\
\text { Reduced Joint stiffness } \\
\text { Ideal for patients with previously } \\
\text { harvested }\end{array}$ \\
\hline Disadvantage & $\begin{array}{l}\text { Pain in donor site } \\
\text { Larger incision } \\
\text { Permanent sensation loss } \\
\text { Possibility of patella } \\
\text { fracture } \\
\text { Ant knee pain }\end{array}$ & $\begin{array}{l}\text { Slower healing process for soft } \\
\text { tissue-to-bone } \\
\text { High incidence of tunnel widening } \\
\text { Harvest-technical demanding } \\
\text { Diffuse multiligamentous laxity }\end{array}$ & $\begin{array}{l}\text { Q-muscle atrophy } \\
\text { Violation of extensor } \\
\text { mechanism }\end{array}$ & $\begin{array}{l}\text { Risk of infection } \\
\text { Increased transmitted diseases } \\
\text { Reduced graft strength } \\
\text { Low grade immune rejection } \\
\text { Cost \& decreased availability } \\
\text { Delayed incorporation }\end{array}$ \\
\hline
\end{tabular}

ACL: anterior cruciate ligament, BPTB: bone-tendon-bone grafts.

ACL reconstruction. Although the preservation of a remnant ACL stump might lead to incorrect tibial tunnel placement or cyclops formation ${ }^{26)}$, it has many theoretical advantages including accelerated revascularization and ligamentization, preservation of the proprioceptive nerve fibers, enhanced biological environment for healing, and reduced incidence of tibial bone tunnel enlargement ${ }^{5,25-28)}$. Ahn et al. $^{27)}$ reported that remnant preserving ACL reconstruction provided good clinical outcomes and stabilities without compromising accuracy of tunnel position. However, cyclops lesions were found in 12 out of 48 patients on MRI even though they did not have any limitation in extension (Table 2) ${ }^{15,22,25,26,29,30)}$. Mifune et al. ${ }^{31)}$ reported that remnant preserving selective bundle augmentation showed good anterior and rotational stability in patients with only AM or PL tear, and they recommended remnant preserving augmentation for partial ACL tears. In terms of tunnel widening, Zhang et al. ${ }^{32)}$ showed less tibial tunnel enlargement after remnant preserving ACL reconstruction than remnant removing ACL reconstruction, but no difference was seen in clinical outcomes.

Although some studies showed that remnant preserving ACL reconstruction provided promising results in terms of clinical outcomes and tunnel widening, we could not find any literature that this technique improves proprioception or stability and allows for rapid rehabilitation compared to traditional remnant removing ACL reconstruction. Moreover, there are no prospective randomized studies comparing the remnant preserving and traditional ACL reconstruction. In conclusion, the present literature does not conclusively support the benefits of remnant preserving ACL reconstruction.

\section{Graft Materials for Anterior Cruciate Ligament Re- construction}

Graft choice for ACL reconstruction is influenced by patient age, activity level, gender, associated injuries, degree of laxity, and planned concomitant operations. As a general guideline, autografts are recommended for young patients because it is presumed that these patients are more active. Allografts are not as strong as autografts and are only indicated in patients undergoing revision ACL surgery or in those who only want to return to lower demand activities. Allografts in ACL reconstruction have advantages including decreased operative time, smaller incisions, and less post-operative pain. However, autografts are still preferred because allografts carry the possibility of disease transmission (Table 3).

In a meta-analysis study and systematic review on the comparison of clinical outcomes of ACL reconstruction using autografts and allograft, there was no difference in the outcome scores, laxity, clinical failure rates, and return to sports ${ }^{33)}$ (Tables 4,5$)^{34-41)}$.

The two most commonly used autografts in ACL reconstruction are the patellar tendon (PT) autograft and the four-strand hamstring (HS) tendon autograft consisting of the gracilis and semitendinosus tendons. The other sources of autografts include the quadriceps tendons. Although there has been little research on quadriceps tendon grafts, several recent studies support their use in ACL reconstruction ${ }^{42}$. To date, there have been a number of prospective and retrospective studies comparing patellar tendon bone-tendon-bone grafts (BPTB) and four-strand hamstring grafts (DSTG; double semitendinosus and gracilis tendon grafts). 
Table 4. Instrumented Laxity Measurement of $>5 \mathrm{~mm}$ Pooled according to Graft Source

\begin{tabular}{|c|c|c|c|}
\hline Study of subgroup & Autograft & Allograft & Odds ratio $(95 \% \mathrm{CI})$ \\
\hline Barrett et al. ${ }^{34)}$ & 25 & 38 & $0.20(0.01-4.02)$ \\
\hline Chang et al. ${ }^{35)}$ & 22 & 34 & $1.03(0.16-6.74)$ \\
\hline Edgar et al. ${ }^{36)}$ & 37 & 46 & $3.97(0.40-39.86)$ \\
\hline Harner et al. ${ }^{37)}$ & 26 & 64 & $1.25(0.21-7.28)$ \\
\hline Kleipool et al. ${ }^{38)}$ & 26 & 36 & $1.42(0.19-10.77)$ \\
\hline Peterson et al..$^{39)}$ & 30 & 30 & $5.35(0.25-116.31)$ \\
\hline Saddemi et al. ${ }^{40)}$ & 25 & 18 & $0.23(0.01-5.95)$ \\
\hline Total & 191 & 266 & $1.23(0.52-2.92)$ \\
\hline
\end{tabular}

Odd ratio was calculated using the Mantel-Haenszel method and random-effects analysis model.

CI: confidence interval.

Some studies found similar laxity values and functional results between the two types of graft tissues ${ }^{43-45)}$, while others ${ }^{2,46,47)}$ found the patellar tendon graft produced significantly better results in terms of stability, but this did not correlate with the functional outcome. The advantage of the hamstring tendon autograft is relatively low overall postoperative pain, especially anterior knee pain. Thus, it would be the preferred choice of graft in ACL reconstruction for patients with a low pain tolerance, a job that requires kneeling, or a history of knee pain. In addition, it would be a better option for patients concerned about aesthetics because it requires a relatively small incision. The disadvantage is that it takes relatively long time for the graft to heal into the tunnel since there is no "bone-to-bone" healing.

Despite the disadvantage, the hamstring autograft has recently been widely used as the primary graft of choice in ACL reconstruction because of the relatively low postoperative knee pain, low comorbidity due to preservation of the extensor mechanism by not violating the patellar tendon and quadriceps tendon, and little clinical and functional difference compared to the BPTB.

\section{Fixation Devices for ACL Reconstruction}

The fixation device for graft in ACL reconstruction should be secure and allow graft healing within the tunnel. Because more aggressive rehabilitation program has been adopted in ACL reconstruction recently, the strength of fixation device should be enough to allow immediate range of motion exercises, weight bearing, and early return to sports without any loss of fixation strength. Over the past 10 years, significant advances in fixation have led to the development of many different fixation devices for bony and soft tissue graft fixation.
Table 5. Clinical Failures Pooled according to Graft Source

\begin{tabular}{lccc}
\hline Study of subgroup & Autograft & Allograft & Odds ratio (95\% CI) \\
\hline Barrett et al. $^{34)}$ & 25 & 38 & $0.49(0.02-12.52)$ \\
Chang et al. $^{35)}$ & 33 & 46 & $0.19(0.01-3.72)$ \\
Edgar et al. $^{36)}$ & 37 & 46 & $1.94(0.31-12.28)$ \\
Kleipool et al. $^{38)}$ & 26 & 36 & Not estimable \\
Peterson et al. $^{39)}$ & 30 & 30 & $1.00(0.06-16.76)$ \\
Saddemi et al. $^{40)}$ & 31 & 19 & $0.60(0.04-10.20)$ \\
Victor et al. $^{41)}$ & 48 & 25 & $0.07(0.00-1.34)$ \\
Total & 280 & 240 & $0.61(0.21-1.79)$ \\
\hline
\end{tabular}

Odd ratio was calculated using the Mantel-Haenszel method and random-effects analysis model.

$\mathrm{CI}$ : confidence interval.

\section{Bone Plug Fixation Device}

Metal or bio- interference screws are most commonly used fixation device for bone plug in ACL reconstruction. Metal interference screws designed by Kurosaka have been used as the standard fixation device in ACL reconstruction with patellar tendon autograft ${ }^{48}$. However, with the increasing use of hamstring soft tissue grafts, bioabsorbable interference screws, poly-L-lactic acid (PLLA) screws, and polyglyconate screws ${ }^{49)}$ are becoming more popular. While the bioabsorbable screw has the advantages, such as incorporation into the surrounding tissue, almost no need for implant removal, and less interference with $\mathrm{MRI}^{50)}$, it seems to provide clinical results similar to those of metal screws according to a systematic review.

Cross biodegradable or metal pins (Rigid Fix; DePuy Mitek Inc., Raynham, MA, USA) can be used for the fixation of the bone plug. The principal failure mode with cross pins in this utilization is bone block fracture, and the cross pin fixation strength improves with larger bone plug diameters. Cross pins showed similar fixation strength as interference fixation screws with bone plugs $^{51)}$. The RetroScrew (Arthrex, Naples, FL, USA), recently designed to be inserted from the articular side of the tibia, may actually increase the graft tension as the screw is advanced ${ }^{199}$. In a recent biomechanical study, however, the fixation strength and fixation failure load of RetroScrew was not found to be as good as interference screws ${ }^{52}$.

\section{Soft Tissue Fixation Device}

Interference screws are also commonly used for the fixation of soft tissue graft. The adequate length of interference screw is required for improved fixation strength (30-35 mm screws). Cross biodegradable pins (Rigid Fix) and RetroScrews (Arthrex) can also be used for the fixation of soft tissue graft. When used 
in ACL reconstruction using a hamstring tendon, they produce clinical results that can be comparable to those of reconstruction using interference screws and the EndoButton ${ }^{22,51,53)}$.

The EndoButton CL (Smith \& Nephew Endoscopy, Andover, MA, USA), an extra cortical suspensory fixation device, has been widely used as a fixation device for the hamstring graft on the femoral side. Although EndoButton has a higher failure load and less stiffness than interference screws, it induces some micro motion of the graft within the bone tunnel during loading, and can be a cause of tunnel widening ${ }^{49)}$. Baumfeld et al. ${ }^{54)}$ reported that 2 cross pin fixation resulted in less femoral tunnel widening than the EndoButton fixation. On the other hand, Kong et al. ${ }^{55}$ suggested that the clinical results were comparable between the cross pin fixation and EndoButton fixation and there was no significant difference in femoral tunnel widening between the two fixation devices. An advantage, however, of the same is that extra cortical fixation creates a long bone-tendon interface, making it suitable for many types of ACL reconstruction techniques as well as single- and double-bundle reconstruction. Suture tying around the screw post is also another established technique. This fixation system has adequate strength for graft fixation and also has advantages of tendon healing into the bony tunnel.

In summary, most of modern fixation devices have enough strength to fix the graft in ACL reconstruction regardless of graft materials. All systems have their specific advantages and disadvantages. Therefore, the choice of a fixation device should be based on the type of graft or quality of bone.

\section{Conclusions}

Although there are still no definite conclusions whether double bundle ACL reconstruction can provide better clinical results than single bundle technique, the main trend for ACL reconstruction has shifted to anatomic reconstruction regardless of single bundle or double bundle techniques during the past 10 years. In the literature, the type of graft or fixation device did not make significant differences in clinical outcomes or stability of ACL reconstruction. Because there are a variety of options available today, selection of optimum combination should be individualized to the patient's condition and the experience of the surgeon. Further advances in surgical techniques should continue to be developed so as to restore near normal knee kinematics and anatomy.

\section{Conflict of Interest}

No potential conflict of interest relevant to this article was reported.

\section{References}

1. Buoncristiani AM, Tjoumakaris FP, Starman JS, Ferretti M, $\mathrm{Fu} \mathrm{FH}$. Anatomic double-bundle anterior cruciate ligament reconstruction. Arthroscopy. 2006;22:1000-6.

2. Freedman KB, D’Amato MJ, Nedeff DD, Kaz A, Bach BR Jr. Arthroscopic anterior cruciate ligament reconstruction: a metaanalysis comparing patellar tendon and hamstring tendon autografts. Am J Sports Med. 2003;31:2-11.

3. Abebe ES, Moorman CT 3rd, Dziedzic TS, Spritzer CE, Cothran RL, Taylor DC, Garrett WE Jr, DeFrate LE. Femoral tunnel placement during anterior cruciate ligament reconstruction: an in vivo imaging analysis comparing transtibial and 2-incision tibial tunnel-independent techniques. Am J Sports Med. 2009;37:1904-11.

4. Prodromos CC, Fu FH, Howell SM, Johnson DH, Lawhorn K. Controversies in soft-tissue anterior cruciate ligament reconstruction: grafts, bundles, tunnels, fixation, and harvest. J Am Acad Orthop Surg. 2008;16:376-84.

5. Fu FH, Jordan SS. The lateral intercondylar ridge: a key to anatomic anterior cruciate ligament reconstruction. J Bone Joint Surg Am. 2007;89:2103-4.

6. Abebe ES, Kim JP, Utturkar GM, Taylor DC, Spritzer CE, Moorman CT 3rd, Garrett WE, DeFrate LE. The effect of femoral tunnel placement on ACL graft orientation and length during in vivo knee flexion. J Biomech. 2011;44:191420.

7. Yasuda K, Kondo E, Ichiyama H, Kitamura N, Tanabe Y, Tohyama H, Minami A. Anatomic reconstruction of the anteromedial and posterolateral bundles of the anterior cruciate ligament using hamstring tendon grafts. Arthroscopy. 2004;20:1015-25.

8. Vaquero J, Vidal C, Cubillo A. Intra-articular traumatic disorders of the knee in children and adolescents. Clin Orthop Relat Res. 2005;(432):97-106.

9. Brucker PU, Imhoff AB. Functional assessment after acute and chronic complete ruptures of the proximal hamstring tendons. Knee Surg Sports Traumatol Arthrosc. 2005;13:4118.

10. Tohyama H, Kondo E, Hayashi R, Kitamura N, Yasuda K. Gender-based differences in outcome after anatomic double- 
bundle anterior cruciate ligament reconstruction with hamstring tendon autografts. Am J Sports Med. 2011;39:1849-57.

11. Zaffagnini S, Bruni D, Marcheggiani Muccioli GM, Bonanzinga T, Lopomo N, Bignozzi S, Marcacci M. Single-bundle patellar tendon versus non-anatomical double-bundle hamstrings ACL reconstruction: a prospective randomized study at 8-year minimum follow-up. Knee Surg Sports Traumatol Arthrosc. 2011;19:390-7.

12. Suomalainen P, Jarvela T, Paakkala A, Kannus P, Jarvinen M. Double-bundle versus single-bundle anterior cruciate ligament econstruction: a prospective randomized study with 5-year results. Am J Sports Med. 2012;40:1511-8.

13. Xu M, Gao S, Zeng C, Han R, Sun J, Li H, Xiong Y, Lei G. Outcomes of anterior cruciate ligament reconstruction using single-bundle versus double-bundle technique: metaanalysis of 19 randomized controlled trials. Arthroscopy. 2013;29:357-65.

14. Steiner ME, Battaglia TC, Heming JF, Rand JD, Festa A, Baria M. Independent drilling outperforms conventional transtibial drilling in anterior cruciate ligament reconstruction. Am J Sports Med. 2009;37:1912-9.

15. Ahn JH, Choi SH, Wang JH, Yoo JC, Yim HS, Chang MJ. Outcomes and second-look arthroscopic evaluation after double-bundle anterior cruciate ligament reconstruction with use of a single tibial tunnel. J Bone Joint Surg Am. 2011;93:1865-72.

16. Seon JK, Park SJ, Lee KB, Yoon TR, Seo HY, Song EK. Stability comparison of anterior cruciate ligament between double- and single-bundle reconstructions. Int Orthop. 2009;33:425-9.

17. Woo SL, Kanamori A, Zeminski J, Yagi M, Papageorgiou $\mathrm{C}, \mathrm{Fu} \mathrm{FH}$. The effctiveness of reconstruction of the anterior cruciate ligament with hamstrings and patellar tendon: a cadaveric study comparing anterior tibial and rotational loads. J Bone Joint Surg Am. 2002;84:907-14.

18. Rue JP, Lewis PB, Parameswaran AD, Bach BR Jr. Singlebundle anterior cruciate ligament reconstruction: technique overview and comprehensive review of results. J Bone Joint Surg Am. 2008;90 Suppl 4:67-74.

19. Sastre S, Popescu D, Nunez M, Pomes J, Tomas X, Peidro L. Double-bundle versus single-bundle ACL reconstruction using the horizontal femoral position: a prospective, randomized study. Knee Surg Sports Traumatol Arthrosc. 2010;18:32-6.

20. Araki D, Kuroda R, Kubo S, Fujita N, Tei K, Nishimoto K, Hoshino Y, Matsushita T, Matsumoto T, Nagamune K, Ku- rosaka M. A prospective randomised study of anatomical single-bundle versus double-bundle anterior cruciate ligament reconstruction: quantitative evaluation using an electromagnetic measurement system. Int Orthop. 2011;35:43946.

21. Giron F, Cuomo P, Edwards A, Bull AM, Amis AA, Aglietti P. Double-bundle "anatomic" anterior cruciate ligament reconstruction: a cadaveric study of tunnel positioning with a transtibial technique. Arthroscopy. 2007;23:7-13.

22. Kim MK, Lee BC, Park JH. Anatomic single bundle anterior cruciate ligament reconstruction by the two anteromedial portal method: the comparison of transportal and transtibial techniques. Knee Surg Relat Res. 2011;23:213-9.

23. Lubowitz JH, Konicek J. Anterior cruciate ligament femoral tunnel length: cadaveric analysis comparing anteromedial portal versus outside-in technique. Arthroscopy. 2010;26:1357-62.

24. Seo SS, Kim CW, Kim JG, Jin SY. Clinical results comparing transtibial technique and outside in technique in single bundle anterior cruciate ligament reconstruction. Knee Surg Relat Res. 2013;25:133-40.

25. Lee BI, Kwon SW, Kim JB, Choi HS, Min KD. Comparison of clinical results according to amount of preserved remnant in arthroscopic anterior cruciate ligament reconstruction using quadrupled hamstring graft. Arthroscopy. 2008;24:5608.

26. Ahn JH, Lee YS, Yoo JC, Chang MJ, Koh KH, Kim MH. Clinical and second-look arthroscopic evaluation of repaired medial meniscus in anterior cruciate ligament-reconstructed knees. Am J Sports Med. 2010;38:472-7.

27. Ahn JH, Lee YS, Ha HC. Anterior cruciate ligament reconstruction with preservation of remnant bundle using hamstring autograft: technical note. Arch Orthop Trauma Surg. 2009;129:1011-5.

28. Kim SJ, Jo SB, Kim TW, Chang JH, Choi HS, Oh KS. A modified arthroscopic anterior cruciate ligament doublebundle reconstruction technique with autogenous quadriceps tendon graft: remnant-preserving technique. Arch Orthop Trauma Surg. 2009;129:403-7.

29. Gao K, Chen S, Wang L, Zhang W, Kang Y, Dong Q, Zhou H, Li L. Anterior cruciate ligament reconstruction with LARS artificial ligament: a multicenter study with 3- to 5-year follow-up. Arthroscopy. 2010;26:515-53.

30. Gohil S, Annear PO, Breidahl W. Anterior cruciate ligament reconstruction using autologous double hamstrings: a comparison of standard versus minimal debridement techniques 
using MRI to assess revascularisation: a randomised prospective study with a one-year follow-up. J Bone Joint Surg Br. 2007;89:1165-71.

31. Mifune Y, Ota S, Takayama K, Hoshino Y, Matsumoto T, Kuroda R, Kurosaka M, Fu FH, Huard J. Therapeutic advantage in selective ligament augmentation for partial tears of the anterior cruciate ligament: results in an animal model. Am J Sports Med. 2013;41:365-73.

32. Zhang Q, Zhang S, Cao X, Liu L, Liu Y, Li R. The effect of remnant preservation on tibial tunnel enlargement in ACL reconstruction with hamstring autograft: a prospective randomized controlled trial. Knee Surg Sports Traumatol Arthrosc. 2012 Dec 15. [Epub]. http://dx.doi.org/10.1007/ s00167-012-2341-7.

33. Carey JL, Dunn WR, Dahm DL, Zeger SL, Spindler KP. A systematic review of anterior cruciate ligament reconstruction with autograft compared with allograft. J Bone Joint Surg Am. 2009;91:2242-50.

34. Barrett G, Stokes D, White M. Anterior cruciate ligament reconstruction in patients older than 40 years: allograft versus autograft patellar tendon. Am J Sports Med. 2005;33:150512.

35. Chang SK, Egami DK, Shaieb MD, Kan DM, Richardson $\mathrm{AB}$. Anterior cruciate ligament reconstruction: allograft versus autograft. Arthroscopy. 2003;19:453-62.

36. Edgar CM, Zimmer S, Kakar S, Jones H, Schepsis AA. Prospective comparison of auto and allograft hamstring tendon constructs for ACL reconstruction. Clin Orthop Relat Res. 2008;466:2238-46.

37. Harner CD, Olson E, Irrgang JJ, Silverstein S, Fu FH, Silbey M. Allograft versus autograft anterior cruciate ligament reconstruction: 3- to 5-year outcome. Clin Orthop Relat Res. 1996;(324):134-44.

38. Kleipool AE, Zijl JA, Willems WJ. Arthroscopic anterior cruciate ligament reconstruction with bone-patellar tendonbone allograft or autograft: a prospective study with an average follow up of 4 years. Knee Surg Sports Traumatol Arthrosc. 1998;6:224-30.

39. Peterson RK, Shelton WR, Bomboy AL. Allograft versus autograft patellar tendon anterior cruciate ligament reconstruction: a 5-year follow-up. Arthroscopy. 2001;17:9-13.

40. Saddemi SR, Frogameni AD, Fenton PJ, Hartman J, Hartman W. Comparison of perioperative morbidity of anterior cruciate ligament autografts versus allografts. Arthroscopy. 1993;9:519-24.

41. Victor J, Bellemans J, Witvrouw E, Govaers K, Fabry G.
Graft selection in anterior cruciate ligament reconstruction: prospective analysis of patellar tendon autografts compared with allografts. Int Orthop. 1997;21:93-7.

42. DeAngelis JP, Fulkerson JP. Quadriceps tendon: a reliable alternative for reconstruction of the anterior cruciate ligament. Clin Sports Med. 2007;26:587-96.

43. Markolf KL, Hame SL, Hunter DM, Oakes D, Gause P. Biomechanical effects of femoral notchplasty in anterior cruciate ligament reconstruction. Am J Sports Med. 2002;30:83-9.

44. Shaieb MD, Kan DM, Chang SK, Marumoto JM, Richardson $\mathrm{AB}$. A prospective randomized comparison of patellar tendon versus semitendinosus and gracilis tendon autografts for anterior cruciate ligament reconstruction. Am J Sports Med. 2002;30:214-20.

45. Struewer J, Ziring E, Oberkircher L, Schuttler KF, Efe T. Isolated anterior cruciate ligament reconstruction in patients aged fifty years: comparison of hamstring graft versus bonepatellar tendon-bone graft. Int Orthop. 2013;37:809-17.

46. Biau DJ, Tournoux C, Katsahian S, Schranz PJ, Nizard RS. Bone-patellar tendon-bone autografts versus hamstring autografts for reconstruction of anterior cruciate ligament: meta-analysis. BMJ. 2006;332:995-1001.

47. Goldblatt JP, Fitzsimmons SE, Balk E, Richmond JC. Reconstruction of the anterior cruciate ligament: meta-analysis of patellar tendon versus hamstring tendon autograft. Arthroscopy. 2005;21:791-803.

48. Matsumoto A, Yoshiya S, Muratsu H, Matsui N, Yagi M, Kuroda R, Kurosaka M. Mechanical evaluation of a soft tissue interference screw with a small diameter: significance of graft/bone tunnel cross-sectional area ratio. Knee Surg Sports Traumatol Arthrosc. 2006;14:330-4.

49. Stener S, Ejerhed L, Sernert N, Laxdal G, Rostgard-Christensen L, Kartus J. A long-term, prospective, randomized study comparing biodegradable and metal interference screws in anterior cruciate ligament reconstruction surgery: radiographic results and clinical outcome. Am J Sports Med. 2010;38:1598-605.

50. Cheung P, Chan WL, Yen CH, Cheng SC, Woo SB, Wong TK, Wong WC. Femoral tunnel widening after quadrupled hamstring anterior cruciate ligament reconstruction. J Orthop Surg (Hong Kong). 2010;18:198-202.

51. Harilainen A, Sandelin J, Jansson KA. Cross-pin femoral fixation versus metal interference screw fixation in anterior cruciate ligament reconstruction with hamstring tendons: results of a controlled prospective randomized study with 2-year follow-up. Arthroscopy. 2005;21:25-33. 
52. Chang HC, Nyland J, Nawab A, Burden R, Caborn DN. Biomechanical comparison of the bioabsorbable RetroScrew system, BioScrew XtraLok with stress equalization tensioner, and 35-mm Delta Screws for tibialis anterior grafttibial tunnel fixation in porcine tibiae. Am J Sports Med. 2005;33:1057-64.

53. Harilainen A, Sandelin J. A prospective comparison of 3 hamstring ACL fixation devices: Rigidfix, BioScrew, and Intrafix: randomized into 4 groups with 2 years of follow-up. Am J Sports Med. 2009;37:699-706.
54. Baumfeld JA, Diduch DR, Rubino LJ, Hart JA, Miller MD, Barr MS, Hart JM. Tunnel widening following anterior cruciate ligament reconstruction using hamstring autograft: a comparison between double cross-pin and suspensory graft fixation. Knee Surg Sports Traumatol Arthrosc. 2008;16:1108-13.

55. Kong CG, In Y, Kim GH, Ahn CY. Cross pins versus endobutton femoral fixation in hamstring anterior cruciate ligament reconstruction: minimum 4-year follow-Up. Knee Surg Relat Res. 2012;24:34-9. 